\title{
Rancang Bangun Sistem Informasi Pelayanan Jasa Home Service Dengan Model Waterfall Pada CV. Gian Motor Autoservice
}

\author{
Giyan eko $^{1}$, Yunita $^{2}$, Hilda amalia ${ }^{3}$ \\ ${ }^{1}$ Universitas Bina Sarana Informatika \\ e-mail: giyaneko14@gmail.com \\ ${ }^{2}$ Universitas Bina Sarana Informatika \\ e-mail: yunita.ynt@bsi.ac.id \\ ${ }^{3}$ Universitas Bina Sarana Informatika \\ e-mail: hilda.ham@bsi.ac.id
}

\begin{abstract}
Transportation is needed by humans as the times develop and there is an increase in mobility of activities. The development of motorized vehicles every year is increasing and diverse. Of course, the increasing number of vehicles, the more people who need service or repair services they have. In the current era, it requires the use of technology. The technology that is widely used is web-based technology, the web is used by thousands of people as a good promotional media. In designing information systems a model that can be used is needed, the selection of the right model is an important factor in the success of building a system. The Waterfall Model is a simple model and is suitable for developing software with specifications that do not change. So with the waterfall methode is able to complete the design of service information system home service.
\end{abstract}

Keyword: information system, home service, waterfall

\section{PENDAHULUAN}

Transportasi dibutuhkan oleh manusia seiring berkembangnya zaman dan adanya peningkatan mobilitas kegiatan. Kebutuhan akan sarana transportasi membuat masyarakat Indonesia berbondong-bondong memilih transportasi yang nyaman untuk digunakan dalam kehidupan sehari-hari. Terhitung hingga Juli 2016 di Indonesia mencapai 125 juta unit dengan kontribusi sebanyak $10-15 \%$ dari mobil. Perkembangan kendaraa $\mathrm{n}$ tersebut terutama mobil di imbangi dengan bertambahnya penduduk yang semakin meningkat di setiap tahunnya (Oktaviastuti \& Wijaya, 2017). Tentunya semakin meningkatnya kendaraan, semakin meningkat pula masyarakat yang membutuhkan jasa service atau reparasi kendaraan yang mereka miliki.

Perawatan adalah sebuah operasi atau aktivitas yang harus dilakukan secara berkala dengan tujuan untuk melakukan pergantian kerusakan peralatan dengan resources yang ada (Kusnadi \& Taryana, 2017)

Peluang usaha ini dimanfaatkan oleh para pemilik modal untuk mendirikan perusahaan jasa bengkel yang menawarkan produk berupa jasa perawatan atau service kendaraan khususnya mobil. Berangkat dari hal tersebut ternyata membawa dampak semakin banyak pula jenis usaha bengkel mobil yang berdiri dengan tujuan melayani kebutuhan service, serta reparasi mobil. Diperlukan alternatif strategi bersaing (Strategy in Competition) yang tepat agar perusahaan mampu bersaing dengan kompetitor lainnya(MZ, 2014). CV. Gian Motor Autoservice merupakan perusahaan yang bergerak dibidang penyediaan barang, jasa service, dan perawatan kendaraan bermotor khususnya mobil. Dalam perannya, CV. Gian Motor Autoservice dalam dunia automotif, memberikan jasa service, reparasi, menjual spare part dan perawatan mobil, mulai dari perawatan berkala sampai service kerusakan mobil dengan cara mendatangi langsung ke rumah atau lokasi customer (Home Service) khusus untuk wilayah Jabodetabek. Diketahui sampai dengan saat ini sudah ada ratusan customer dan 2 (dua) instansi pemerintahan yang bekerja sama dan menggunakan jasa service pada CV. Gian Motor Autoservice. Cutomer dan instansi pemerintahan tersebut megetahui informasi adanya jasa service dan perawatan kendaraan bermotor khususnya mobil pada CV. Gian Motor Autoservice hanya dari mulut ke mulut (word of mouth). Komunikasi dari mulut ke mulut (word of mouth) dinilai sangat efektif dalam memperlancar proses pemasaran dan mampu memberikan keuntungan kepada perusahaan ataupun kepada komunitas yang ada, dan tidak membutuhkan biaya yang begitu besar, namun dapat memberikan efektivitas yang sangat tinggi (Rahayu, 2014) . 
Namun word of mouth terbatas pada area persebaran informasi, pada era digital saat ini dengan adanya media internet dapat memperluas persebaran informasi yaang diharapkan dan dapat meningkatkan value untuk perusahaan.

Pada era saat ini menuntut penggunaan teknologi, semua kehidupan tergantung kepada mesin, teknologi diciptakan untuk mempermudah kehidupan manusia (Reza Palevi, 2013). Teknologi yang marak digunakan adalah teknologi berbasis web, web digunakan oleh ribuan orang sebagai media promosi yang baik (Wahyu, Wijaya, Mulyanto, \& Mustakim, 2010). Dalam merancang sistem informasi diperlukan model yang dapat digunakan, pemilihan model yang tepat merupakan faktor penting dalam keberhasilan membangun sistem. Model Waterfall merupakan model yang sederhana dan cocok untuk pengembangan perangkat lunak dengan spesifikasi yang tidak berubah-ubah. Konsep model waterfall menjadi salah satu solusi dalam menangani dan meminimalisir kesalahan-kesalahan yang terjadi pada pengolahan data (Mutiah \& Apriana, 2018)

Berdasarkan latar belakang masalah yang penulis paparkan diatas, maka penulis dapat merumuskan masalah yang telah diteliti adalah: "Bagaimana merancang sebuah sistem yang menarik dan Easy to Use, agar mempermudah customer memperoleh informasi yang dibutuhkan dari berbagai lokasi, dan juga sebagai media promosi secara universal.

\section{METODELOGI PENELITIAN}

A. Pengumpulan data

1. Metode Observasi

Merupakan metode pengamatan yang dilakukan untuk mendapatkan informasi mengenai keadaan yang berlangsung di lapangan dengan tujuan untuk mendapatkan sistem yang berjalan sehingga dapat mengidentifikasi masalah yang ada.

2. Metode Studi Pustaka

Merupakan metode mendapatkan informasi dengan menggunakan pembelajaran dari beberapa artikel ilmiah atau buku ajar yang sesuai dengan penelitian yang dilakukan.

B. Analisa Kebutuhan

1. Kebutuhan Pengguna

Dalam sistem berbasis web ini terdapat empat pengguna yang saling berinteraksi dalam lingkungan sistem, yaitu: Pengunjung, User (customer), Staff, dan Owner. Keempat pengguna tersebut memiliki karakteristik interaksi yang berbeda dan memiliki kebutuhan informasi yang berbeda pula, sebagai berikut:

1.1. Skenario Pengunjung

a. Mengunjungi website

b. Melihat harga suku cadang

1.2. Skenario Kebutuhan User

a. Melihat informasi website perusahaan

b. Mendaftar sebagai user

c. Melihat informasi dan daftar harga suku cadang

d. Melakukan pemesanan jasa

e. Memberikan Komentan atau kritik dan saran atas pelayanan jasa

1.3. Skenario Kebutuhan Staff

a. Memproses data pemesanan jasa yang masuk

b. Mencetak bukti pemesanan, untuk di jadikan sebagai kwitansi pembayaran

c. Mengelola data

d. Membuat laporan pemesanan

1.4. Skenario Kebutuhan Owner

a. Melihat laporan transaksi dan pemesanan

b. Mengelola data staff

2. Kebutuhan Sistem

a. Pengguna harus melakukan login terlebih dahulu untuk dapat mengakses sistem berbasis web ini, dengan memasukan username untuk login user (customer) lalu NIP (Nomer Induk Pegawai) untuk login bagian staff dan Owner, disertakan dengan memasukan password agar privasi masingmasing pengguna tetap terjaga.

b. Sistem dapat melakukan kalkulasi stok secara otomatis.

c. Seluruh pengguna harus melakukan logout apabila telah selesai menggunakan website.

\section{HASIL DAN PEMBAHASAN}

Tahapan dalam metode waterfall (A.S \& Shalahuddin, 2014) :

1. Analisa Kebutuhan perangkat lunak Proses pengumpulan kebutuhan dilakukan secara intensif untuk mespesifikasikan kebutuhan perangkat lunak agar dapat dipahami perangkat lunak seperti apa yang dibutuhkan oleh user.

2. Desain

Desain perangkat lunak adalah proses multi langkah yang fokus pada desain pembuatan program perangkat lunak 
termasuk struktur data, arsitektur perangkat lunak, representasi antarmuka, dan prosedur pengodean. Dalam tahapan ini digambarkan dengan rancangan:

A. Rancangan Diagram Use Case

1. Use case Pendaftaran

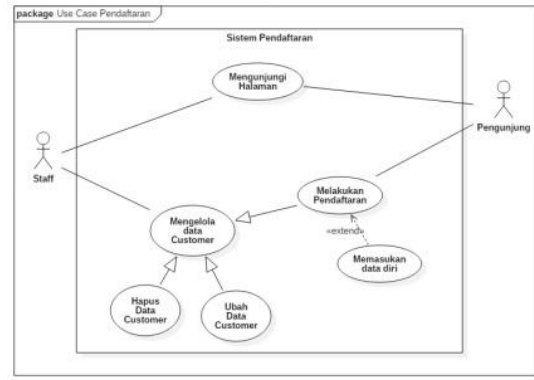

Sumber: (peneliti,2018)

Gambar 1 Use Case Diagram Pendaftaran

2. Use Case Pemesanan

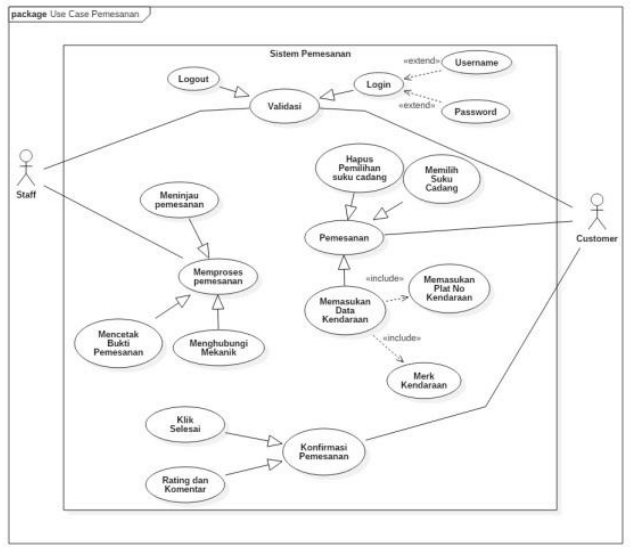

Sumber: (peneliti,2018)

Gambar 2 Use Case Diagram Pemesanan

3. Use Case Laporan

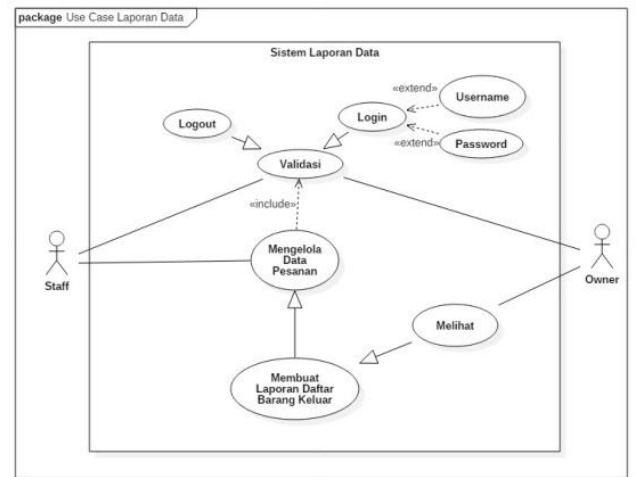

Sumber: (peneliti,2018)

Gambar 3 Use Case Diagram Laporan

\section{B. Rancangan Diagram Aktivitas}

1. Diagram Akitivitas Login

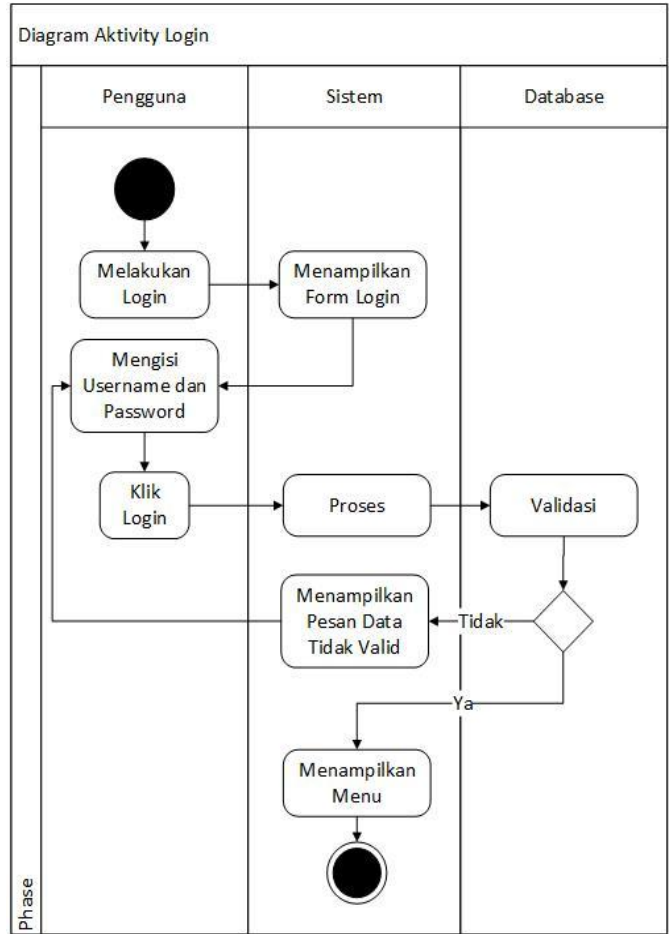

Sumber: (peneliti,2018)

Gambar 4 Diagram Aktivitas Login

2. Diagram Aktivitas Pelayanan Jasa

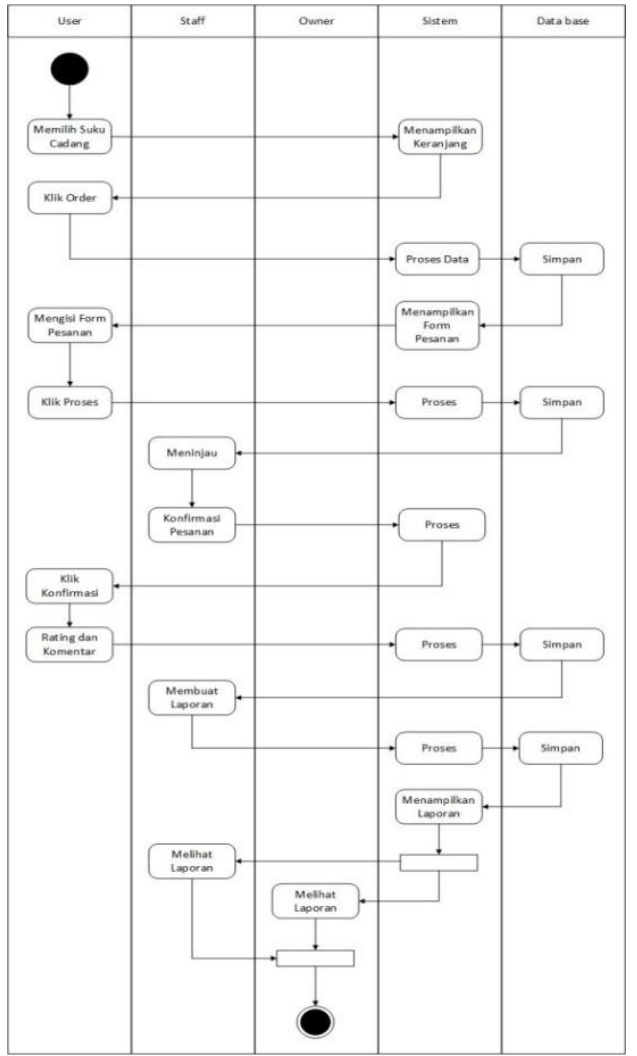

Sumber: (peneliti,2018)

Gambar 5 Diagram Aktivitas

Pelayanan Jasa 


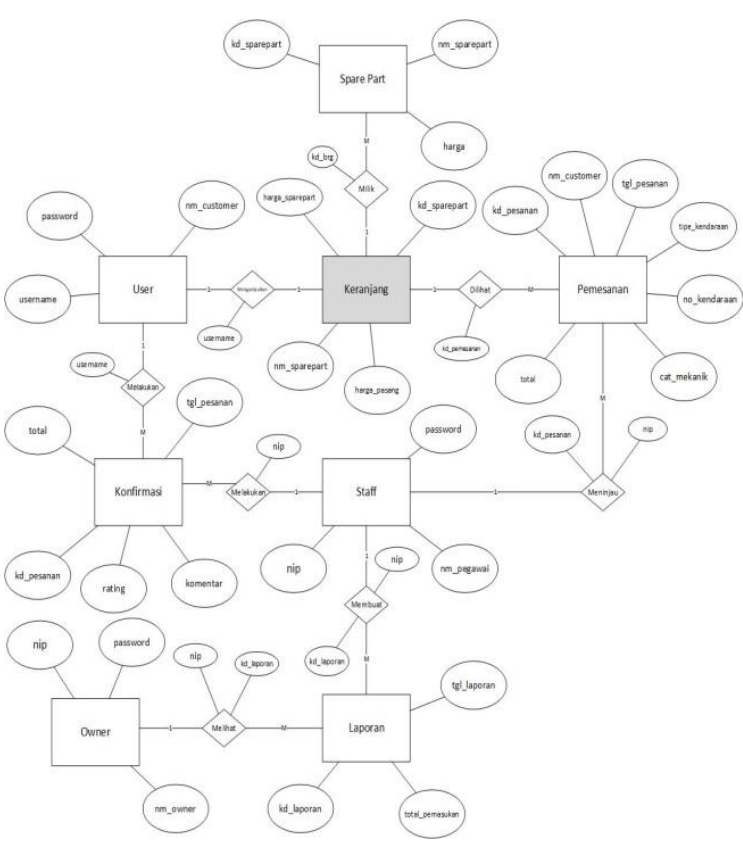

Sumber: (peneliti,2018)

Gambar 6 Entity Relational Diagram

\section{Logical Record Structure}

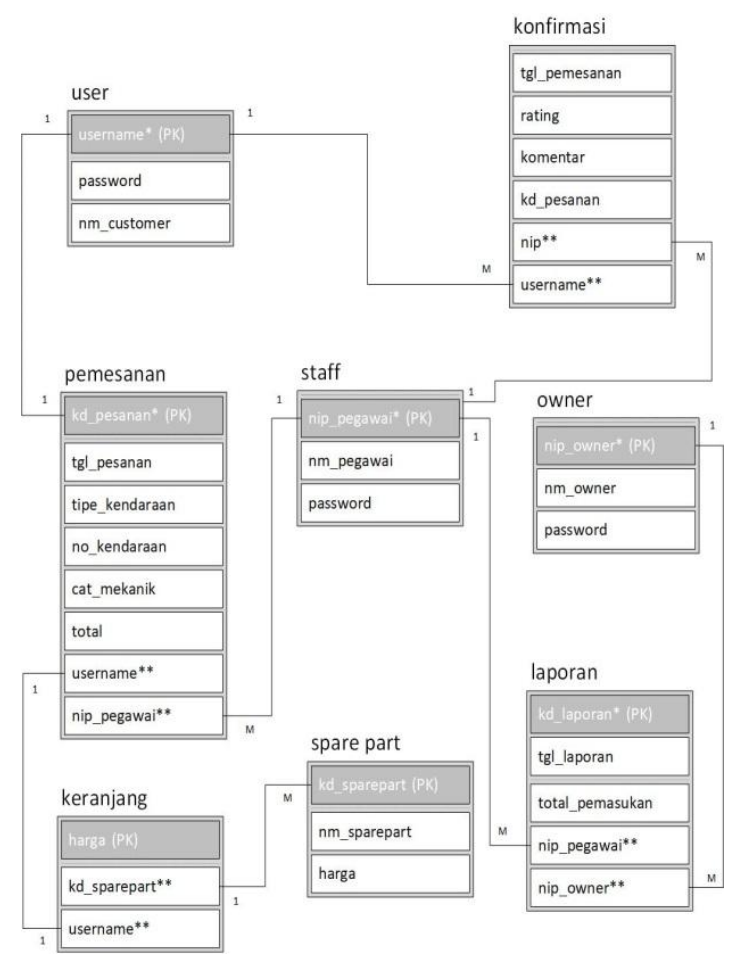

Sumber: (peneliti,2018)

Gambar 7 Logical Record Structure

\section{Pembuatan Kode Program}

Desain harus ditranslasikan ke dalam program perangkat lunak, hasil dari tahap ini adalah program komputer sesuai dengan desain yang telah dibuat pada tahap desain. Untuk perancangan program pelayanan service ini menggunakan script php dan menggunakan aplikasi design dreamweaver 8.

\section{Pengujian}

Untuk pengujian terhadap program pelayanan jasa service dilakukan dengan menggunakan metode black box testing, yang dilakukan dengan tujuan memastikan output yang dihasilkan sesuai dengan inputan, dan validasi yang dibuat untuk program.

Hasil pengujian blackbox testing halaman login

Tabel 1. Pengujian Form Login Admin

\begin{tabular}{|c|c|c|c|c|c|}
\hline No & $\begin{array}{c}\text { Skenario } \\
\text { Pengujian }\end{array}$ & Test Case & $\begin{array}{c}\text { Hasil yang } \\
\text { di harapkan }\end{array}$ & $\begin{array}{c}\text { Hasil } \\
\text { Pengujian }\end{array}$ & $\begin{array}{c}\text { Kesi } \\
\text { mpul } \\
\text { an }\end{array}$ \\
\hline 1. & $\begin{array}{l}\text { Mengetikan } \\
\text { username } \\
\text { dan } \\
\text { password } \\
\text { tidak di isi } \\
\text { kemudian } \\
\text { klik tombol } \\
\text { masuk }\end{array}$ & $\begin{array}{l}\text { Username: } \\
\text { (admin) } \\
\text { Password: } \\
\text { (kosong) }\end{array}$ & $\begin{array}{l}\text { Sistem akan } \\
\text { menolak lalu } \\
\text { muncul } \\
\text { pesan } \\
\text { "Periksa } \\
\text { username } \\
\text { dan } \\
\text { password } \\
\text { anda" }\end{array}$ & $\begin{array}{l}\text { Sesuai } \\
\text { dengan } \\
\text { harapan }\end{array}$ & Valid \\
\hline 2. & $\begin{array}{l}\text { Mengetikan } \\
\text { username } \\
\text { tidak diisi } \\
\text { dan } \\
\text { password } \\
\text { di isi } \\
\text { kemudian } \\
\text { klik tombol } \\
\text { masuk }\end{array}$ & $\begin{array}{l}\text { Username: } \\
\text { (kosong) } \\
\text { Password: } \\
\text { (admin) }\end{array}$ & $\begin{array}{l}\text { Sistem akan } \\
\text { menolak } \\
\text { lalu muncul } \\
\text { pesan } \\
\text { "Periksa } \\
\text { username } \\
\text { dan } \\
\text { password } \\
\text { anda" }\end{array}$ & $\begin{array}{l}\text { Sesuai } \\
\text { dengan } \\
\text { harapan }\end{array}$ & Valid \\
\hline 3. & $\begin{array}{l}\text { Mengetikan } \\
\text { username } \\
\text { dengan } \\
\text { benar dan } \\
\text { mengisi } \\
\text { password } \\
\text { salah } \\
\text { kemudian } \\
\text { klik tombol } \\
\text { masuk }\end{array}$ & $\begin{array}{l}\text { Username: } \\
\text { (admin) } \\
\text { (benar) } \\
\text { Password } \\
: \\
\text { (maruko) } \\
\text { (salah) }\end{array}$ & $\begin{array}{l}\text { Sistem akan } \\
\text { menolak lalu } \\
\text { muncul } \\
\text { pesan } \\
\text { "Periksa } \\
\text { username } \\
\text { dan } \\
\text { password } \\
\text { anda" }\end{array}$ & $\begin{array}{l}\text { Sesuai } \\
\text { dengan } \\
\text { harapan }\end{array}$ & Valid \\
\hline 4. & $\begin{array}{l}\text { Mengetikan } \\
\text { username } \\
\text { dan } \\
\text { password } \\
\text { dengan } \\
\text { data yang } \\
\text { benar } \\
\text { kemudian } \\
\text { klik tombol } \\
\text { masuk }\end{array}$ & $\begin{array}{l}\text { Username: } \\
\text { Admin } \\
\text { (benar) } \\
\text { Password: } \\
\text { Admin } \\
\text { (benar) }\end{array}$ & $\begin{array}{l}\text { Login } \\
\text { berhasil dan } \\
\text { Akan } \\
\text { muncul } \\
\text { halaman } \\
\text { home admin }\end{array}$ & $\begin{array}{l}\text { Sesuai } \\
\text { dengan } \\
\text { harapan }\end{array}$ & Valid \\
\hline
\end{tabular}

Sumber: (peneliti,2018) 


\section{KESIMPULAN}

Dari hasil penelitian diketahui bahwa sistem informasi pelayanan jasa home service berbasis web dapat meningkatkan kinerja sistem pelayanan jasa service dengan menggunkan metode waterfall. Dari hasil penelitian dapat diketahui bahwa sistem pelayanan jasa service mempunyai peranan yang sangat penting bagi setiap pelaku bisnis. Sistem pelayanan yang efesien, efektif dapat meningkatkan dan mempermudah didalam pelayanan jasa ke konsumen dengan hasil yang lebih cepat, tepat dan akurat sehingga mampu membrikan saran pendukung terhadap permasalahan didalam pelayanan jasa home service yang dihadapi.

\section{REFENSI}

A.S, R., \& Shalahuddin, M. (2014). Rekayasa Perangkat Lunak. Informatika. Bandung.

Kusnadi, K., \& Taryana, T. (2017). Usulan Waktu Penggantian Optimum Komponen Mesin Gas Engine (Prechamber Gas Valve) Dengan Model Age-Based Replacement Di Pt. Xyz. Jurnal Teknologi, $8(1), \quad 45$. https://doi.org/10.24853/jurtek.8.1.45-52

Mutiah, S. K., \& Apriana, V. (2018). Penerapan Model Waterfall Pada Sistem Informasi Pembelian Bahan Baku Roti. Jurnal Perspektif, XVI(2).

MZ, H. (2014). Analisis Pengaruh Pelayanan Jasa Service Sepeda Motor Terhadap Kepuasan Pelanggan Pada Bengkel. Jurnal Desiminasi TeknologiDesiminasi Teknologi, 2(2), 173-182.
Oktaviastuti, B., \& Wijaya, H. S. (2017). Urgensi pengendalian kendaraan bermotor Di indonesia. Jurnal Rekayasa Teknik Sipil, 2(1), 1-4.

Rahayu, D. D. (2014). PENGARUH WORD OF MOUTH DAN BRAND COMMUNITY KOMUNITAS SEPAK BOLA DI PEKAN BARU TERHADAP BRAND IMAGE. Jurnal Ekonomi, 22, 561-565.

Reza Palevi, A. K. (2013). ANALISIS DAN PERANCANGAN SISTEM INFORMASI PENERIMAAN PESERTA DIDIK BARU BERBASIS WEBSITE PADA SMP NEGERI 2 MOJOSONGO Pendahuluan Landasan Teori \& Tinjauan Umum. Jurnal Ilmiah DASI, 14(04), 2-7.

Wahyu, S., Wijaya, S., Mulyanto, A., \& Mustakim, M. (2010). Berbasis Web Dan Wap. In Sistem Penerimaan Mahasiswa Baru (Vol. 10, pp. 395-404). Yogyakarta.

\section{Biodata Peneliti}

Giyan Eko, Lulus dari AMIK BSI Jakarta Program Studi Manajemen Informatika tahun 2018

Yunita, Lulus dari Program Studi Magister Ilmu Komputer STMIK Nusa Mandiri tahun 2013. Dosen pada program studi Komputerisasi Akuntansi AMIK BSI JAKARTA

Hilda Amalia, Lulus dari Program Studi Magister Ilmu Komputer STMIK Nusa Mandiri tahun 2012. Dosen pada program studi Manajemen Informatika AMIK BSI JAKARTA. 